\title{
Projection of premature mortality from noncommunicable diseases for 2025: A model based study from Hunan Province, China, 1990-2016
}

\author{
Qiaohua Xu ${ }^{1}$, Maigeng Zhou ${ }^{2}$, Donghui Jin ${ }^{1}$, Xinying Zeng $^{2}$, Jinlei Qi ${ }^{2}$, Li Yin $^{1}$, Yuan Liu $^{1}$, Lei Yin $^{1}$, Yuelong \\ Huang Corresp. 1 \\ ${ }^{1}$ Department of NCDs Control and Prevention, Hunan Provincial Center for Disease Control and Prevention, Changsha, Hunan, China \\ 2 National Center for Chronic and Non-communicable Disease Control and Prevention, Chinese Center for Disease Control and Prevention, Beijing, China \\ Corresponding Author: Yuelong Huang \\ Email address: hylong410@126.com
}

Background. In 2011, the United Nations set a target to reduce premature mortality from noncommunicable diseases (NCDs) by $25 \%$ by 2025 . While studies have reported the target in some countries, no studies have been done in China. This study aims to project the ability to reach the target in Hunan Province, China, and establish the priority for future interventions.

Methods. We conducted the study during 2019-2020. From the Global Burden of Disease Study 2016, we extracted death data for Hunan during 1990-2016 for four main NCDs, namely cancer, cardiovascular disease (CVD), chronic respiratory diseases, and diabetes. We generated estimates for 2025 by fitting a linear regression to the premature mortality over the most recent trend identified by a joinpoint regression model. We also estimated excess premature mortality attributable to unfavorable changes over time.

Results. The rate of premature mortality from all NCDs in Hunan will be $19.5 \%$ (95\% Cl: 19.0\%-20 1\%) by 2025 , with the main contributions being from CVD $(8.2 \%, 95 \% \mathrm{Cl}: 7.9 \%-8.5 \%)$ and cancer $(7.9 \%, 95 \%$ $\mathrm{Cl}: 7.8 \%-8.1 \%)$. Overall, it will be impossible to achieve the target, with a relative reduction of $16.4 \%$. Women may be able to meet the target except with respect to cancer, and men will not except with respect to chronic respiratory diseases. Most of the unfavorable changes have occurred since 2008-2009.

Discussion. More urgent efforts, especially for men, should be exerted in Hunan by integrating population-wide interventions into a stronger health-care system. In the post lock-down COVID-19 era in China, reducing the NCD risk factors can also lower the risk of death from COVID-19. 
1 Projection of premature mortality from Noncommunicable Diseases for 2025:

2 a model based study from Hunan Province, China, 1990-2016

3

4 Qiaohua $\mathrm{Xu}{ }^{1}$, Maigeng Zhou ${ }^{2}$, Donghui Jin ${ }^{1}$, Xinying Zeng ${ }^{2}$, Jinlei Qi ${ }^{2}$, Li Yin ${ }^{1}$, Yuan Liu ${ }^{1}$, $5 \quad$ Lei Yin ${ }^{1}$, Yuelong Huang ${ }^{1}$

6

71 Department of NCDs Control and Prevention, Hunan Provincial Center for Disease Control

8 and Prevention, Changsha, Hunan, China

9

102 National Center for Chronic and Non-communicable Disease Control and Prevention,

11 Chinese Center for Disease Control and Prevention, Beijing, China

12

13

Correspondence: Yuelong Huang, hylong410@126.com

14 
28 Abstract

Background. In 2011, the United Nations set a target to reduce premature mortality from noncommunicable diseases (NCDs) by $25 \%$ by 2025 . While studies have reported the target in some countries, no studies have been done in China. This study aims to project the ability to reach the target in Hunan Province, China, and establish the priority for future interventions.

Methods. We conducted the study during 2019-2020. From the Global Burden of Disease Study 2016, we extracted death data for Hunan during 1990-2016 for four main NCDs, namely cancer, cardiovascular disease (CVD), chronic respiratory diseases, and diabetes. We generated estimates for 2025 by fitting a linear regression to the premature mortality over the most recent trend identified by a joinpoint regression model. We also estimated excess premature mortality attributable to unfavorable changes over time.

Results. The rate of premature mortality from all NCDs in Hunan will be 19.5\% (95\% CI: $19.0 \%-20 \cdot 1 \%)$ by 2025 , with the main contributions being from CVD $(8.2 \%, 95 \%$ CI: $7.9 \%$ $8.5 \%)$ and cancer $(7.9 \%, 95 \%$ CI: $7.8 \%-8.1 \%)$. Overall, it will be impossible to achieve the target, with a relative reduction of $16.4 \%$. Women may be able to meet the target except with respect to cancer, and men will not except with respect to chronic respiratory diseases. Most of the unfavorable changes have occurred since 2008-2009.

Discussion. More urgent efforts, especially for men, should be exerted in Hunan by integrating population-wide interventions into a stronger health-care system. In the post lock-down COVID19 era in China, reducing the NCD risk factors can also lower the risk of death from COVID-19.

\section{Introduction}

1 Premature death from noncommunicable diseases (NCDs) remains a major global development challenge in the 21 st century. Each year, a total of 15 million people around the world die from NCDs between the ages of 30 and $70 .{ }^{1}$ As the most populous country in the world, China is 
54

55

56

particularly affected by this challenge. A combination of market globalization, rapid urbanization, modifiable risk factors, and population aging over the past decades has led to an NCD epidemic in China: NCDs, mainly including cardiovascular disease (CVD), cancer, diabetes and chronic respiratory diseases, account for $70 \%$ of the disease burden and are responsible for $89 \%$ of all deaths in the Chinese population. ${ }^{1,2}$ They have rapidly become the top killer in the country. ${ }^{3}$ Meanwhile, the high burden of NCDs reduces effective labor supply and productivity; it also increases treatment costs, thus lowering the accumulation of physical capital and impeding economic growth. ${ }^{4}$

In response to the global NCD epidemic, the United Nations (UN) set a target in 2011 for member countries to achieve a relative $25 \%$ reduction from the 2010 level in premature mortality from NCDs by 2025 (referred to as the 25 by 25 target). ${ }^{5}$ Although studies have estimated the 25 by 25 targets in some countries, ${ }^{5-7}$ no reports for China have been produced. In addition, because the benefits of controlling NCDs produce are realized gradually, it is urgent to ascertain the target feasibility in China to identify essential efforts for future, more effective interventions. Our study therefore projects whether the UN target can be met by 2025 in Hunan Province, China, and when and how much excess premature mortality from NCDs due to unfavorable changes occurred to establish the priority for future, more effective interventions. Additionally, we hope that our research provides a useful reference for countries or regions that are also working to better reduce the risk of premature deaths from NCDs.

\section{Materials and Methods}

\section{Data source}

We conducted the projection in Hunan Province, Central China, where both the burden of years of lost (YLLs) and the ratio of observed to expected disability-adjusted life-years (DALYs) are significantly higher than the national average. ${ }^{8}$ Based on the Global Burden of Disease Study (GBD) 2016 for China, we extracted death data from 1990 to 2016 for the above four main 
81 NCDs for Hunan by age, sex, year, and underlying causes. The GBD study was a collaboration

82

83

84

85

86

87

88

89

90

91

92

93

94

95

96

97

98

102 103

104

105 between the Institute for Health Metrics and Evaluation, University of Washington, and the Chinese Center for Disease Control and Prevention (CDC). With a highly standardized method, the mortality was estimated for China based on multisource death surveillance systems or surveys conducted in the country, which mainly consisted of national disease surveillance points system, population death information registry and management system, national maternal and child health surveillance system, local cancer registry and some other mortality reports. ${ }^{11}$

According to the International Classification of Diseases tenth revision (ICD-10), we distributed the ICD-10 codes for the four NCDs as follows: cancer: C00-C97; CVD: I00-I99; chronic respiratory diseases: J30-J98; and diabetes: E10-E14.

\section{Statistical Analysis}

We set premature mortality from NCDs (also written as premature NCD mortality) as the key indicator for the analysis, with age-standardized rates (ASRs) standardized to the 2010 China census population as a minor indicator. Premature mortality is defined by the WHO as the probability of dying between the age of 30 and 70 from NCDs and is calculated by age-specific death rates with a life table method in the following manner: 10

1) Age-specific death rates in 5-year age groups (e.g. 30-34...65-69) were calculated by

$$
{ }_{5}^{*} M x=\frac{\text { Total deaths from four NCDs aged }[x, x+5)}{\text { Mid }- \text { year population aged }[x, x+5)} .
$$

2) The ${ }_{5}^{*} M_{x}$ was translated into age-specific probability of death : ${ }_{5}^{*} q_{x}=\frac{{ }_{5}^{*} M_{x} * 5}{1+{ }_{5}^{*} M_{x} * 2.5}$.

3) The probability of death for persons aged 30-70 was calculated last:

$$
{ }_{40}^{*} q_{30}=1-\prod\left(1-{ }_{5}^{*} q_{x}\right) \text {. }
$$

We performed a joinpoint regression to examine trends in premature NCD mortality, with a maximum of three joinpoints set for the analysis. The joinpoint regression describes continuous 
106

107

108

109

110

111

112

changes by connecting several line segments on a log scale and identifies statistically significant changes with a Monte Carlo permutation test. ${ }^{11,12}$ The three following indicators, annual percentage change (APC), average APC (AAPC) and overall percent change, reflected different changes in temporal trends. The former two indicators were calculated by $A P C_{i}=\left\{\exp \left(\mathrm{b}_{\mathrm{i}}\right)-1\right\} \mathrm{x}$ 100, and $A A P C=\left\{\exp \left(\frac{\sum w_{i} b_{i}}{\sum w_{i}}-1\right\} \times 100\right.$, where $b_{i}$ represents the slope coefficients for each segment in the years studied, and $w_{i}$ represents the length of each segment in the intervals. The final indicator was calculated with an AAPC-based exponentiation function by first converting the AAPC to the predicted single-year change and then exponentiating to the number of study years minus one to produce the overall change and its magnitude, which was finally converted to a percent change. ${ }^{11}$

We projected premature mortality from NCDs (as well as ASRs) with $95 \%$ confidence intervals (CIs) for 2025 by fitting a linear regression over the most recent trend identified by the joinpoint model. To estimate the ability to meet the UN target in Hunan, we compared the projected premature mortality from NCDs in the province in 2025 with the level in 2010 to find the relative reduction with the following formula:

$$
\text { relative reduction }(\%)=\frac{(\text { projected premature mortality } 2025-\text { observed premature mortality } 2010)}{\text { observed premature mortality } 2010} * 100 \text {. }
$$

This allowed us to determine if the relative reduction would be greater than $25 \%$.

To identify excess premature NCD mortality due to unfavorable changes (slowed, stalled or reversed),${ }^{13}$ we performed a three-step estimation: First, each most significant APC for the four NCDs was selected as a projection point to find the expected premature mortality, assuming it would continue to decline to 2025 at the same level as the selected APCs. Second, we compared the total differences among observed (1990-2016)-projected (2017-2025) premature mortality with the expected ones to obtain the absolute excess premature mortality. Third, the differences 
131

132

133

134

135

136

137

138

139

140

141

142

143

144

145

146

147

148

149

150

151

152

153

154

6

were divided by expected premature mortality to obtain the relative change in the excess premature mortality.

Experimental verification was carried out to evaluate the prediction accuracy of the Joinpoint model. Death data of all NCDs combined during 1990-2011 from the GBD was selected as a sample, to project premature mortality rate for 2012-2016. The results were then compared with the real data with three metrics: Mean Square Error (MSE), Percentage Error (PE) and Mean Absolute Percentage Error (MAPE). ${ }^{14}$ Among them, $M S E=\frac{1}{n} \sum_{i=1}^{n}\left(\hat{y}-y_{i}\right)^{2}$,

$P E=\frac{\left|\hat{y}-y_{i}\right|}{y_{i}} \times 100 \%, M A P E=\frac{1}{n} \sum_{i=1}^{n} \frac{\left|\hat{y}-y_{i}\right|}{y_{i}} \times 100 \%$, where $\hat{y}$ represents projected value, $y_{i}$ represents observed value. MAPE less than $10 \%$ were considered good accurate. ${ }^{15}$

Analyses for temporal trends and projection through 2025 were performed using the Joinpoint program version 4.7.0.0 (Statistical Research and Applications Branch, National Cancer Institute, USA). Line art was produced by R version 3.6.0 (R Foundation for Statistical Computing, Vienna, Austria). A p-value $<0.05$ was considered statistically significant.

\section{Results}

Temporal trends during 1990-2016 are shown as the AAPC, APC and overall percent change (Table S1). Premature mortality from all NCDs combined was projected to be $19.5 \%$ (95\% CI 19.0\%-20.1\%). The top contributor to premature mortality was CVD $(8.2 \%, 95 \%$ CI: $7.9 \%$ $8.5 \%)$, followed by cancer $(7.9 \%, 95 \%$ CI $7.5 \%-8.3 \%)$. The premature mortality rates for chronic respiratory diseases and diabetes were $1.2 \%$ (95\% CI 1.2\%-1.3\%) and $0.6 \%$ (95\% CI 0.5\%$0.6 \%$ ), respectively. Except for a narrow difference in diabetes, men had greater premature mortality from NCDs than women, with an approximately two-fold difference. Regarding the 
155

156

157

158

159

160

161

162

163

164

165

166

167

168

169

170

171

172

173

174

175

176

177

178

179

180

181

182

ASRs in 2025, there will be 377.7 deaths (95\% CI 367.5-387.8) per 100,000 persons for all

NCDs, with the main contributors being cancer (ASR: 152.5 deaths per 100,000 persons) and CVD (ASR: 143.7 deaths per 100,000 persons) (Table 1).

Figure 1 presents the temporal trends for NCDs and the ability to reach the 25 by 25 target in Hunan. A similar trend between the premature mortality and ASRs can be observed. With all NCDs combined, it is not possible to achieve the $\mathrm{UN}$ target, as the relative reduction is $16.4 \%$. Among the subcategories, cancer is the least likely to reach the target, with the smallest relative reduction (11.8\%). Another disease failing to meet the target would be CVD, with a $22.1 \%$ relative reduction. Both chronic respiratory diseases and diabetes shared a more than $25 \%$ relative reduction in premature mortality, with the former showing the greater reduction, at $44.0 \%$.

A difference was seen in the distribution of the top two NCDs for both sexes (Figure 2). In men, CVD remained the top contributor to premature mortality over time, followed by cancer. In women, cancer will take this position in 2025 due to a faster decline in CVD than in cancer. Another difference was the ability to reach the target: a relative reduction of $31.6 \%$ in women but only $7.8 \%$ in men was projected. In women, except for a slightly smaller reduction for cancer (23.0\%), the three other subcategories all showed a greater than $25 \%$ reduction. The situation is grim, however, for men, in whom only chronic respiratory diseases achieved a greater than $25 \%$ reduction (29.5\%), and the result for diabetes even showed a $15.8 \%$ increase.

During1990-2025, a total absolute excess premature NCD mortality rate of $55.4 \%$ and relative excess change of $19.4 \%$ were estimated (Figure $3 \mathrm{~A}$ ). These unfavorable changes mostly occurred from 2008-2009. Among the subcategories (Figure 3: B to D), CVD showed both higher absolute excess premature mortality (29.6\%) and relative excess change (22.8\%) than cancer (absolute excess premature mortality: $14.8 \%$; relative change: $11.4 \%)$. The greatest excess change (42.1\%) was estimated for chronic respiratory disease, despite its much lower absolute excess premature 
183 184

185

186

187

188

mortality. The absolute excess premature mortality from diabetes was estimated at only $0.8 \%$, whereas its relative excess reached $11.8 \%$ during the same period.

The Joinpoint model verification showed that for all NCDs combined projected for 2012-2016 (Table 2), the MSE was estimated to be 0.476 . A range of $0.70 \%$ to $4.48 \%$ was estimated for PE, resulting in a MAPE of $2.79 \%$. Among men, the MSE would be 0.721 , and the PE would be from $0.65 \%$ to $4.61 \%$, resulting in the MAPE at $2.65 \%$. Among women, the matching values were projected to be: MSE at $0.303, \mathrm{PE}$ ranging from $0.99 \%$ to $4.68 \%$, and MAPE at $3.26 \%$. These results indicated a good prediction accuracy for the Joinpoint model.

\section{Discussion}

Although previous studies have estimated premature mortality from NCDs, each had a different focus. For instance, in the study by Kontis V et al., 5 the authors highlighted the impacts of achieving the WHO agreed six risk factors (tobacco and alcohol use, salt intake, obesity, raised blood pressure and glucose) targets on reaching the 25 by 25 target. The authors calculated a time-based population impact fraction to identify relative reductions in the premature mortality through reanalyses and meta-analyses of epidemiological studies. In another study by Norheim OF et al., ${ }^{16}$ the authors proposed a more ambitious goal of avoiding $40 \%$ of premature deaths from all causes globally by 2030, beyond the current UN sustainable development goal (reducing premature mortality from NCDs by one-third by 2030). They reviewed the UN-based overall 1970-2010 mortality and WHO-based cause-specific 2000-2010 mortality. They concluded such a target could be achieved by moderately accelerating the current mortality decrease during 2000-2010.

Unlike these two studies, our study estimated the 25 by 25 target's feasibility at the local rather than the global level. As NCDs account for high proportions of the disease burden and all deaths, 
209

210

211

212

213

214

215

216

217

218

219

220

221

222

223

224

225

226

227

228

229

230

231

232

233

234

235

as mentioned above, we emphasized premature deaths from NCDs rather than all causes to set future control priorities. Based on a Joinpoint regression model, we derived 1990-2016 mortality for Hunan from the GBD 2016 to project premature mortality from NCDs and the excess situation for 2025, assessing the ability to meet the target here. Through the projection, we found that although premature mortality from NCDs in Hunan has continuously declined since 1990, this decline is insufficient to reach the 25 by 25 target. Especially since 2008-2009, almost all NCDs have experienced unfavorable declines. A possible reason is that the Chinese population has experienced adverse changes in both diet and lifestyle over the past decades. According to the national NCD Risk Factor Surveillances Reports, ${ }^{17,18}$ an increased prevalence of unhealthy diets and physical inactivity has been seen in China. These factors may contribute to the high of $19 \cdot 5 \%$ for premature mortality from total NCDs by 2025 , with the major contributors CVD $(8.2 \%)$ and cancer (7.9\%). Considering the baseline in 2010, although it is highly likely that chronic respiratory disease and diabetes will achieve the target, it will be very difficult for CVD and cancer, causing the total NCD to also be unlikely to meet the target. These results indicate that premature NCD deaths remain an urgent heath challenge in Hunan and across the country and that both cancer and CVD are the priority NCDs that need to be immediately addressed.

We also found that men had much higher premature mortality than women, with only chronic respiratory diseases expected to reach the target. One reason for the substantial gender differences is men's higher prevalence of major NCDs: The prevalence of obesity among men rose more significantly than among women in the decade $2004-2013$, rising from $6.1 \%$ to $14.0 \%$ versus $7.9 \%$ to $14.1 \%$ among women. Men had a higher prevalence of hypertension and diabetes, but lower performance in awareness, treatment, or management of both diseases. ${ }^{18,19}$ In addition, men are more likely than women to be exposed to key risk factors for NCDsin China, also contributing to the difference. ${ }^{3}$, For example, the prevalence of current smoking, drinking (over the past year ), and physical inactivity was $51.8 \%, 58.3 \%$, and $18.2 \%$, respectively in men, compared with $2.3 \%, 15.4 \%$, and $14.3 \%$ in women. It is therefore necessary to implement 
236

237

238

239

240

241

242

243

244

245

246

247

248

249

250

251

252

253

254

255

256

257

258

259

260

261

262

interventions targeting men to tangibly reduce the number of premature NCD deaths.

Most premature NCD deaths can be prevented or delayed by addressing global health risks. Among the modifiable risk factors shared by individuals with NCDs, high blood pressure, smoking, a high-salt diet, and ambient particulate matter pollution (PM, mainly PM2.5) exposure are the four leading factors in China. ${ }^{8}$ Previous studies have shown that premature mortality from NCDs will not show the most favorable decline unless such factors are simultaneously brought under control. ${ }^{5,20}$ Therefore, a multipronged approach is needed to address the above problems; specifically, an integrated strategy combining a population-wide intervention targeting the above factors with a strengthened health care system is urgently needed, because the benefits of reducing NCD risk factors are produced gradually.

\section{Modified high blood pressure control}

Every $10 \mathrm{~mm} \mathrm{Hg}$ reduction in systolic blood pressure significantly lowered the risk of major CVD events (relative risk $0.80,95 \%$ CI $0.77-0.83$ ), resulting in a $13 \%$ reduction in all-cause mortality. ${ }^{21}$ However, high blood pressure management, from awareness to treatment or control, is poor in China. ${ }^{3} \mathrm{~A}$ fact is that only $45 \%$ of Chinese adults with hypertension were aware of their condition, only $30 \%$ were taking anti-hypertensive drugs, and just $7 \%$ had achieved normal blood pressure levels. ${ }^{22}$ A comprehensive, multistage strategy is needed that involves a diet low in salt and rich in polyunsaturated fatty acids, adequate physical activity (no less than a metabolic equivalent of 600 minutes per week), and an improved primary health-care system. Health authorities and professional institutions need to work together to promote an integrated prevention-control-treatment model at the community level leveraging the internet and health information technology. Within such a model, a hypertension outpatient service in community medical institutions and a family doctor contracting service are required to provide individuals with regular hypertension management with respect to screening, essential anti-hypertensive medications, health counseling, follow-up services, etc. It is particularly crucial for 
263

264

265

266

267

268

269

270

271

272

273

274

275

276

277

278

279

280

281

282

283

284

285

286

287

288

289

implementing community-based hypertension screening, as it could have a significant long term impact on systolic blood pressure at the population level. ${ }^{23}$

\section{More ambitious tobacco control measures}

Although the smoking rate has fallen in many high-income countries, it is rising rapidly in China, with a prevalence of $50.5 \%$ in male adults. ${ }^{24}$ It would impose a high macroeconomic burden of tobacco-attributable NCDs for China: Tobacco-attributable NCDs would cost China 16.7 trillion yuan (US\$2.3 trillion in constant 2018 prices) from 2015 to 2030 , equivalent to a $0.9 \%$ annual tax on aggregate income. Secondhand smoke exposure would contribute to $14 \%$ of the burden. ${ }^{25}$ As the hometown for of the two best-selling brands of cigarettes in China, Hunan has been slow to take measures for tobacco control. Many successful policies for tobacco control in other countries have shown that a $50 \%$ reduction in smoking is feasible. ${ }^{26,27-}$ Such feasibility could be achieved by the following actions: First, raise cigarette taxes. Although China implemented a tax linkage in 2015 , raising the wholesale and price taxes on cigarettes from $5 \%$ to $11 \%,{ }^{28}$ cigarettes are much more affordable here than in other countries, with most costing 10 CNY (1.4 USD) a package. It is estimated that a 50\% price increase in cigarettes due to taxes in China would yield an additional 231 million years of life. ${ }^{29}$ Therefore, a higher cigarette tax rate should be the first action. Second, regulate smoking with reference to practices in developed cities such as Beijing, Shanghai, and Shenzhen by comprehensively enacting smoking bans in indoor workplaces, indoor public places, and public transportation. Third, enforce strict bans on tobacco advertising, sponsorship, or any other activity that may weaken smoking control. Fourth, reform the design of cigarette packaging. Cigarette packages in China are all beautifully designed due to a deeply rooted smoking culture, and the warning occupies only a small part of the design space.

Packaging should be redesigned to feature the warning in text and graphics. Fifth, conduct targeted health education. The public's awareness is often confined to "smoking is harmful to health", and many people do not know exactly how smoking is harmful. Health education could be conducted by combining traditional media with new media (such as the Internet or WeChat) 
290

291

292

293

294

295

296

297

298

299

300

301

302

303

304

305

306

307

308

309

310

311

\section{2}

313

314

315

316

or through health campaigns hosted by professional doctors.

\section{A stepwise reduction in salt intake}

High salt consumption is the leading cause of hypertension and is strongly tied to stroke in China. ${ }^{30}$ Chinese people have a daily average salt intake of $12-14 \mathrm{~g},{ }^{30,31}$ much greater than the WHO recommendation of $<5 \mathrm{~g} /$ day. Due to the characteristics of Hunan cuisine, residents' diets are particularly high in salt. We suggest a shift strategy for salt reduction involving both commercial foods and consumer behaviors. First, reduce salt in commercial or processed foods through an industry-wide shift. The key is gradual salt reduction in small steps. Following the UK's practice, ${ }^{32}$ gradually lower salt targets (such as a $20 \%$ decrease) can be set in high-salt categories for the food industry. It is also encouraged that alternatives with the same or better taste be proposed, such as "less salt, more spices" or a "more potassium, less sodium" diet, which have been shown to be helpful in reducing blood pressure and CVD mortality. ${ }^{33}$ Second, shift consumer awareness to action. National salt campaigns can not only raise consumer awareness but also have a remarkable impact on salt intake in the population. In 2017, the Action on Salt China (ASC) program was established with four cluster randomized controlled trial packages. ${ }^{34}$ Hunan participated in the program at five county-level locations, but with 130 county-level areas in the province, actual participation was low. Thus, we suggest expanding salt-reducing interventions from the ASC to the whole province. The salt industry should also take responsibility, for instance, by developing saltshakers with smaller holes or convenient salt intake calculators to help consumers make essential behavior changes.

\section{Reduce harmful alcohol intake}

Health issues attributable to alcohol use, such as CVD and cancer, have been largely underemphasized in China. During the past 30 years, a striking increase has been seen in alcohol use among Chinese men, greater than that in most other countries, ${ }^{35}$ and this trend is forecasted to continue. ${ }^{36}$ This increase is strongly associated with robust economic development and a 
317 deeply rooted alcohol culture. However, the government can play a substantial role in developing 318 alcohol use policies to alter drinking levels. A good example would be Russia, where WHO's

319 recommended best buys interventions for alcohol use, including taxation, availability restrictions, 320 and bans on marketing, were effectively carried out, leading to remarkable changes in both 321 alcohol use and the burden of alcohol-related disease. ${ }^{37}$ For Hunan, similar interventions are also 322 needed and should be broadened through strict restrictions on alcohol advertising on television, 323 legally binding regulations on alcohol sponsorship, and heavy punishments for drunk drivers.

\section{Multisector cooperation to control PM pollution}

326

327

Although the WHO has not set targets for environmental risk factors, PM pollution should be seriously addressed due to its striking position as the fourth-leading risk factor for death in China. ${ }^{8}$ PM pollution causes $3 \cdot 3$ million premature deaths worldwide each year, with China being the largest contributor. ${ }^{38}$ Meanwhile, PM pollution has a huge macroeconomic impact on NCD in China, where total losses from NCDs associated with air pollution were estimated to be \$499 billion (constant 2010 USD) from $2015-2030 .{ }^{39}$ As in many other regions in China, PM2.5 reduction control in Hunan has just begun. The local government released in 2018 a 3-year action plan to reduce the annual PM2.5 concentration to less than $40 \mu \mathrm{g} / \mathrm{m}^{3}$ by $2020,{ }^{40}$ but this plan still falls far short of the WHO guidelines. ${ }^{41}$ Thus, intersector collaboration in public-private partnerships should be encouraged by setting PM2.5 levels as an assessment indicator for local government development, supervising pollution from industrial enterprises, establishing rewardand-punishment mechanisms, prompting responses to heavy pollution weather, etc.

When discussing NCDs control, we must recognize that the COVID-19 is now capturing the world focus. As the COVID-19 pandemic is raging worldwide and spreading fast in many countries, China has largely controlled the epidemic. The Chinese government has spent substantial efforts in controlling the COVID-19 epidemic-- such as lockdown, extension of the lunar new year holiday, and facility isolation of mild to moderate cases using Fangcang shelter 
344 hospitals. ${ }^{42,43}$ However, these measures impose costs, involving human resources, economic

345 losses, public engagement, coordinated governance structures at the national and local levels, etc.

346 Thus we need to think about long-term plans for epidemic control. In the post lock-down

347 COVID-19 era in China, the management of NCDs becomes especially important as people with 348 underlying chronic diseases are more likely to die from COVID- $19 .{ }^{44}$ Reducing the risk factors 349 in NCDs such as smoking and air pollution can also lower the risk of death for COVID-19.45,46

350

351

352

353

354

355

356

357

358

359

360

361

362

363

364

365

366

367

368

369

370

Our study is subject to some limitations. First, the data were derived from the GBD 2016, and all the limitations in the GBD study are also applicable to this study. Second, only five risk factors were addressed in the recommended interventions because the effects of other factors can be partially replaced, but this may affect the most effective control of future premature NCD deaths. Third, we conducted the projection under the current trend, with no consideration for possible greater efforts to reduce NCD risk factors in the future. However, the benefits of lowering the risk factors are produced gradually, which should have a small impact on the results of the present study. Additionally, our projection did not consider the change of age structure of the population during the period studied. This may weaken to some extent, the extrapolation of the model presentation.

1

\section{Conclusions}

Despite a continuous decline in premature mortality from NCDs in Hunan, China, the decline slowed ten years ago. Premature NCD deaths remain high and are unlikely, particularly in men, to reach the 25 by 25 target by 2025. More bold actions combining population-wide interventions for key risk factors with improved health-care systems are urgently needed.

\section{Acknowledgments}

We expressed our thanks to the Institute for Health Metrics and Evaluation, University of Washington and the Chinese CDC, for their collaborative work to produce the GBD results for 
371

372

373

374

375

376

377

378

379

380

381

382

383

384

385

386

387

388

389

390

391

392

393

394

395

396

397

China. We thank Professor Guoqing Hu from Xiangya School of Public Health, Central South University, China, for his advice on paper.

\section{References}

1. WHO. 2018. Noncommunicable diseases fact sheet. Available at https://www.who.int/newsroom/fact-sheets/detail/noncommunicable-diseases(accessedon 2 October2020).

2. China NHCo. The plan for "Healthy China Action (2019-2030)" [Available from:

http://www.nhc.gov.cn/guihuaxxs/s3585u/201907/e9275fb95d5b4295be8308415d4cd1b2.shtml (accessed on June 1, 2020).

3. Li Y, Zeng X, Liu J, Liu Y, Liu S, Yin P, Qi J, Zhao Z, Yu S, Hu Y, He G, Lopez AD, Gao GF, Wang L, Zhou M. . Can China achieve a one-third reduction in premature mortality from non-communicable diseases by 2030? 2017. BMC Med 15(1):132 DOI10.1186/s12916-017-0894-5.

4. Bloom DE, Chen S, Kuhn M, McGovern ME, Oxley L, Prettner K. 2018. The economic burden of chronic diseases: Estimates and projections for China, Japan, and South Korea. J Econ Ageing;

[Epub ahead of print] DOI 10.1016/j.jeoa.2018.09.002.

5. Kontis V, Mathers CD, Rehm J, Stevens GA, Shield KD, Bonita R, Riley LM, Poznyak V, Beaglehole

R, Ezzati M. 2014. Contribution of six risk factors to achieving the $25 \times 25$ non-communicable disease mortality reduction target: a modelling study. Lancet 384(9941):427-437 DOI 10.1016/s01406736(14)60616-4.

6. Malta DC, Andrade SSCA, Oliveira TP, Moura L, Prado RRD, Souza MFM. 2019. Probability of premature death for chronic non-communicable diseases, Brazil and Regions, projections to 2025. Rev Bras Epidemiol 22:e190030 DOI 10.1590/1980-549720190030.

7. Ordunez P, Prieto-Lara E, Pinheiro Gawryszewski V, Hennis AJ, Cooper RS. 2015. Premature Mortality from Cardiovascular Disease in the Americas-Will the Goal of a Decline of " $25 \%$ by 2025 " be Met? PLoS One 10(10):e0141685 DOI 10.1371/journal.pone.0141685. eCollection 2015.

8. Zhou M, Wang H, Zeng X, Yin P, Zhu J, Chen W, Li X, Wang L, Wang L, Liu Y, Liu J, Zhang M, Qi J, Yu S, Afshin A, Gakidou E, Glenn S, Krish VS, Miller-Petrie MK, Mountjoy-Venning WC, Mullany 
398

399

400

401

402

403

404

405

406

407

408

409

410

411

412

413

414

415

416

417

418

419

420

421

422

423

424

EC, Redford SB, Liu H, Naghavi M, Hay SI, Wang L, Murray CJL, Liang X.. 2019. Mortality, morbidity, and risk factors in China and its provinces, 1990-2017: a systematic analysis for the Global Burden of Disease Study 2017. Lancet 394(10204):1145-1158 DOI 10.1016/s0140-6736(19)30427-1.

9. Zeng XY, Li YC, Liu SW, Wang LJ, Liu YN, Liu JM, Zhou MG. 2017. Subnational analysis of probability of premature mortality caused by four main non-communicable diseases in China during 1990-2015 and " Health China 2030" reduction target. Chin J Prev Med. 51(3):209-214 (in Chinese). DOI 10.3760/cma.j.issn.0253-9624.2017.03.004.

10. World Health Organization. 2020. Noncommunicable diseases progress monitor 2020. Geneva: WHO Press. Available at https://www.who.int/publications/i/item/ncd-progress-monitor-2020 (accessed on 2 October, 2020).

11. Jones AM, Isenburg J, Salemi JL, Arnold KE, Mai CT, Aggarwal D, Arias W, Carrino GE, Ferrell E, Folorunso O, Ibe B, Kirby RS, Krapfl HR, Marengo LK, Mosley BS, Nance AE, Romitti PA, Spadafino J, Stock J, Honein MA. 2016. Increasing Prevalence of Gastroschisis--14 States, 1995-2012. MMWR Morb Mortal Wkly Rep 65(2):23-26. DOI 10.15585/mmwr.mm6502a2.

12. Kim HJ, Fay MP, Feuer EJ, Midthune DN. 2000. Permutation tests for joinpoint regression with applications to cancer rates. Stat Med 19(3):335-351 DOI10.1002/(sici)1097-

0258(20000215)19:3<335::aid-sim336>3.0.co;2-z.

13. Yang Q, Tong X, Schieb L, Vaughan A, Gillespie C, Wiltz JL, King SC, Odom E, Merritt R, Hong Y, George MG. 2017. Vital Signs: Recent Trends in Stroke Death Rates - United States, 2000-2015. MMWR Morb Mortal Wkly Rep 66(35):933-939. DOI 10.15585/mmwr.mm6635e1.

14. Zeng SQ. Construction and application of joinpoint regression model for series cumulative data. 2019. Chin J Prev Med 53(10):1075-1080 (in Chinese) DOI 10.3760/cma.j.issn.0253-9624.2019.10.024.

15. Cesnaite G, Domza G, Ramasauskaite D, Volochovic J. 2020. The Accuracy of 22 Fetal Weight Estimation Formulas in Diabetic Pregnancies. Fetal Diagn Ther 47(1):54-59 DOI 10.1159/000500452. 16. Norheim OF, Jha P, Admasu K, Godal T, Hum RJ, Kruk ME, Gómez-Dantés O, Mathers CD, Pan H, Sepúlveda J, Suraweera W, Verguet S, Woldemariam AT, Yamey G, Jamison DT, Peto R. 2015. Avoiding $40 \%$ of the premature deaths in each country, 2010-30: review of national mortality trends to 
425 help quantify the UN sustainable development goal for health. Lancet 385(9964):239-252 DOI

426 10.1016/S0140-6736(14)61591-9.

427 17. National Center for Chronic and Non-communicable Disease Control and Prevention. 2012. Report

428 on Chronic Disease Risk Factor Surveillance in China, 2010. Beijing,China: Military Med. Sci. Press.

429 18. National Center for Chronic and Non-communicable Disease Control and Prevention. 2016. Report

430 on Chronic Disease Risk Factor Surveillance in China, 2013. Beijing, China: Military Med. Sci. Press.

431 19. National Center for Chronic and Non-communicable Disease Control and Prevention. 2010. Report

432 on Chronic Disease Risk Factor Surveillance in China, 2007. Beijing,China: People's Medical Publishing

433 House.

434 20. Beaglehole R, Bonita R, Horton R, Adams C, Alleyne G, Asaria P, Baugh V, Bekedam H, Billo N,

435 Casswell S, Cecchini M, Colagiuri R, Colagiuri S, Collins T, Ebrahim S, Engelgau M, Galea G, Gaziano

436 T, Geneau R, Haines A, Hospedales J, Jha P, Keeling A, Leeder S, Lincoln P, McKee M, Mackay J,

437 Magnusson R, Moodie R, Mwatsama M, Nishtar S, Norrving B, Patterson D, Piot P, Ralston J, Rani M,

438 Reddy KS, Sassi F, Sheron N, Stuckler D, Suh I, Torode J, Varghese C, Watt J; Lancet NCD Action

439 Group; NCD Alliance. 2011. Priority actions for the non-communicable disease crisis. Lancet

440 377(9775):1438-1447 DOI 10.1016/S0140-6736(11)60393-0.

441 21. Ettehad D, Emdin CA, Kiran A, Anderson SG, Callender T, Emberson J, Chalmers J, Rodgers A,

442 Rahimi K. 2016. Blood pressure lowering for prevention of cardiovascular disease and death: a systematic

443 review and meta-analysis. Lancet 387:957-967 DOI 10.1016/S0140- 6736(15)01225-8.

444 22. Lu J, Lu Y, Wang X, Li X, Linderman GC, Wu C, Cheng X, Mu L, Zhang H, Liu J, Su M, Zhao H, 445 Spatz ES, Spertus JA, Masoudi FA, Krumholz HM, Jiang L. 2017. Prevalence, awareness, treatment, and 446 control of hypertension in China: data from 1.7 million adults in a population-based screening study 447 (China PEACE Million Persons Project). Lancet 390:2549-2558 DOI:10.1016/S0140- 6736(17)32478-9.

448 23. Chen S, Sudharsanan N, Huang F, Liu Y, Geldsetzer P, Bärnighausen T. 2019. Impact of community 449 based screening for hypertension on blood pressure after two years: Regression discontinuity analysis in a 450 national cohort of older adults in China. BMJ 366:14064 DOI 10.1136/bmj.14064. PMID: 31296584. 
451

452

453

454

455

456

457

458

459

460

461

462

463

464

465

466

467

468

469

470

471

472

473

474

475

476

24. Prevention CCfDCa. 2019. China adult tobacco survey 2018. Available at http://www.chinacdc.cn/yw_9324/201905/t20190530_202932.html (accessed on June 1, 2020).

25. Chen S, Kuhn M, Prettner K, Bloom DE. 2019. Noncommunicable Diseases Attributable To Tobacco Use In China: Macroeconomic Burden And Tobacco Control Policies. Health Affairs 11 (2019):18321839 DOI 10.1377/hlthaff.2019.00291.

26. Jha P, Peto R. Global effects of smoking, of quitting, and of taxing tobacco. 2014. N Engl J Med 370(1):60-68. DOI 10.1056/NEJMra1308383.

27. Ng M, Freeman MK, Fleming TD, Robinson M, Dwyer-Lindgren L, Thomson B, Wollum A, Sanman E, Wulf S, Lopez AD, Murray CJ, Gakidou E. 2014. Smoking prevalence and cigarette consumption in 187 countries, 1980-2012. JAMA 311(2):183-192. DOI 10.1001/jama.2013.284692.

28. China TMoFo. 2015. A notice on adjustment of consumption tax on cigarettes 2015. Available at http://n.mof.gov.cn/lanmudaohang/zhengcefagui/201505/t20150529_1243724.htm (accessed on June 1, 2020).

29. Verguet S, Gauvreau CL, Mishra S, MacLennan M, Murphy SM, Brouwer ED, Nugent RA, Zhao K, Jha P, Jamison DT. 2015. The consequences of tobacco tax on household health and finances in rich and poor smokers in China: an extended cost-effectiveness analysis. Lancet Glob Health 3(4):e206-e16 DOI $10.1016 / \mathrm{s} 2214-109 x(15) 70095-1$

30. Mente A, O'Donnell M, Rangarajan S, McQueen M, Dagenais G, Wielgosz A, Lear S, Ah STL, Wei L, Diaz R, Avezum A, Lopez-Jaramillo P, Lanas F, Mony P, Szuba A, Iqbal R, Yusuf R, Mohammadifard N, Khatib R, Yusoff K, Ismail N, Gulec S, Rosengren A, Yusufali A, Kruger L, Tsolekile LP, Chifamba J, Dans A, Alhabib KF, Yeates K, Teo K, Yusuf S. 2018. Urinary sodium excretion, blood pressure, cardiovascular disease, and mortality: a community-level prospective epidemiological cohort study. Lancet 392(10146):496-506. DOI 10.1016/S0140-6736(18)31376-X.

31. Du S, Batis C, Wang H, Zhang B, Zhang J, Popkin BM. 2014. Understanding the patterns and trends of sodium intake, potassium intake, and sodium to potassium ratio and their effect on hypertension in China. Am J Clin Nutr 99(2):334-343. DOI 10.3945/ajcn.113.059121. 
477 32. He FJ, Brinsden HC, MacGregor GA. 2014. Salt reduction in the United Kingdom: a successful 478 experiment in public health. J Hum Hypertens. 28(6):345-352. DOI 10.1038/jhh.2013.105.

479 33. Peng YG, Li W, Wen XX, Li Y, Hu JH, Zhao LC. 2014. Effects of salt substitutes on blood pressure: 480 a meta-analysis of randomized controlled trials. Am J Clin Nutr. 100(6):1448-1454. DOI 481 10.3945/ajcn.114.089235.

482 34. He FJ, Zhang P, Li Y, MacGregor GA. 2018. Action on Salt China. Lancet 392(10141):7-9. DOI $483 \quad 10.1016 / \mathrm{S} 0140-6736(18) 31138-3$.

484 35. Jiang H, Room R, Hao W. 2015. Alcohol and related health issues in China: action needed. Lancet 485 Glob Health 3(4):e190-1. DOI 10.1016/S2214-109X(15)70017-3.

486 36. Manthey J, Shield KD, Rylett M, Hasan OSM, Probst C, Rehm J. . 2019. Global alcohol exposure 487 between 1990 and 2017 and forecasts until 2030: a modelling study. Lancet 393(10190):2493-2502. DOI 488 10.1016/S0140-6736(18)32744-2.

489 37. Neufeld M, Rehm J. 2013. Alcohol consumption and mortality in Russia since 2000: are there any 490 changes following the alcohol policy changes starting in 2006? Alcohol Alcohol. 48(2):222-230. DOI 491 10.1093/alcalc/ags134.

492 38. Lelieveld J, Evans JS, Fnais M, Giannadaki D, Pozzer A. 2015. The contribution of outdoor air 493 pollution sources to premature mortality on a global scale. Nature 525(7569):367-371 DOI 494 10.1038/nature15371 [published Online First: 2015/09/19]

495 39. Chen S, Bloom DE. 2019. The macroeconomic burden of noncommunicable diseases associated with 496 air pollution in China. PLoS One 14(4):e0215663 DOI 10.1371/journal.pone.0215663.

497 40. Province PsGoH. 2018. A notice on a three-year action plan for pollution control in Hunan province 498 (2018-2020). Available at 499 http://www.hunan.gov.cn/szf/hnzb/2017_101252/2017nd1q_104056/szfwj_98718/201807/t20180709_50 500 47511.html (accessed on June 1, 2020).

501 41. World Health Organization. Air quality guidelines- global update 2005. Availableat 502 https://www.who.int/airpollution/publications/aqg2005/en/ (accessed on June 1, 2020). 
503

504

505

506

507

508

509

510

511

512

513

514

515

516

517

518

519 Figure legends

520

521

522

523

524

525

526

527

528

529

42. Chen S, Yang J, Yang W, Wang C, Bärnighausen T. 2020. COVID-19 control in China during mass population movements at New Year. Lancet 395(10226):764-766 DOI 10.1016/S0140-6736(20)30421-9.

43. Chen S, Zhang Z, Yang J, Wang J, Zhai X, Bärnighausen T, Wang C. 2020. Fangcang shelter hospitals: a novel concept for responding to public health emergencies. Lancet 2020 395(10232):13051314 DOI 10.1016/S0140-6736(20)30744-3.

44. Wu Z, McGoogan JM. 2020. Characteristics of and important lessons from the coronavirus disease 2019 (COVID-19) outbreak in China: summary of a report of 72314 cases from the Chinese Center for Disease Control and Prevention. Jama 323(13):1239-1242 DOI 10.1001/jama.2020.2648.

45. Chen K, Wang M, Huang C, Kinney PL, Anastas PT. 2020. Air pollution reduction and mortality benefit during the COVID-19 outbreak in China. Lancet Planet Health 4(6):e210-212 DOI $10.1016 / \mathrm{S} 2542-5196(20) 30107-8$.

46. Alqahtani JS, Oyelade T, Aldhahir AM, Alghamdi SM, Almehmadi M, Alqahtani AS, Quaderi S, Mandal S, Hurst JR. 2020. Prevalence, Severity and Mortality associated with COPD and Smoking in patients with COVID-19: A Rapid Systematic Review and Meta-Analysis. PLoSOne15(5):e0233147 DOI 10.1371/journal.pone.0233147.

Figure 1. Premature mortality from NCDs and their ASRs in Hunan, China, from observed years (1990-2016) to projected years (2017-2025). The ability to meet the 25 by 25 target differed across the total NCDs and subcategories: (A) to (C) and (F) will not meet the target with reductions less than $25 \%$, while (D) and (E) will with reductions greater than $25 \%$.

Figure 2. Observed and projected premature NCD mortality by sex in Hunan, China, 1990-2025. Women will meet the target by 2025 except with respect to cancer, while men will not except with respect to chronic respiratory disease. The black dashed line is used to distinguish observed years (1990-2016) from projected years (2017-2025). Five colored lines matching each chart area are shown for the target range and are used to test whether the target will be met (wider than 
530 the chart area in 2025) or not (narrower than the chart area).

531

532 Figure 3. Excess premature mortality from NCDs in Hunan, China, 1990-2025. Yellow line:

533 observed premature mortality from 1990 to 2016 and projected values from 2017 to 2025; grey

534 line: favorable premature mortality from 1990 to 2025; blue area: total absolute excess premature 535 mortality from the NCDs during the period. 
Figure 1

Premature mortality from NCDs and their ASRs in Hunan, China, from observed years (1990-2016) to projected years (2017-2025)

The ability to meet the 25 by 25 target differed across the total NCDs and subcategories: $(A)$ to $(C)$ and $(F)$ will not meet the target with reductions less than $25 \%$, while (D) and (E) will with reductions greater than $25 \%$.
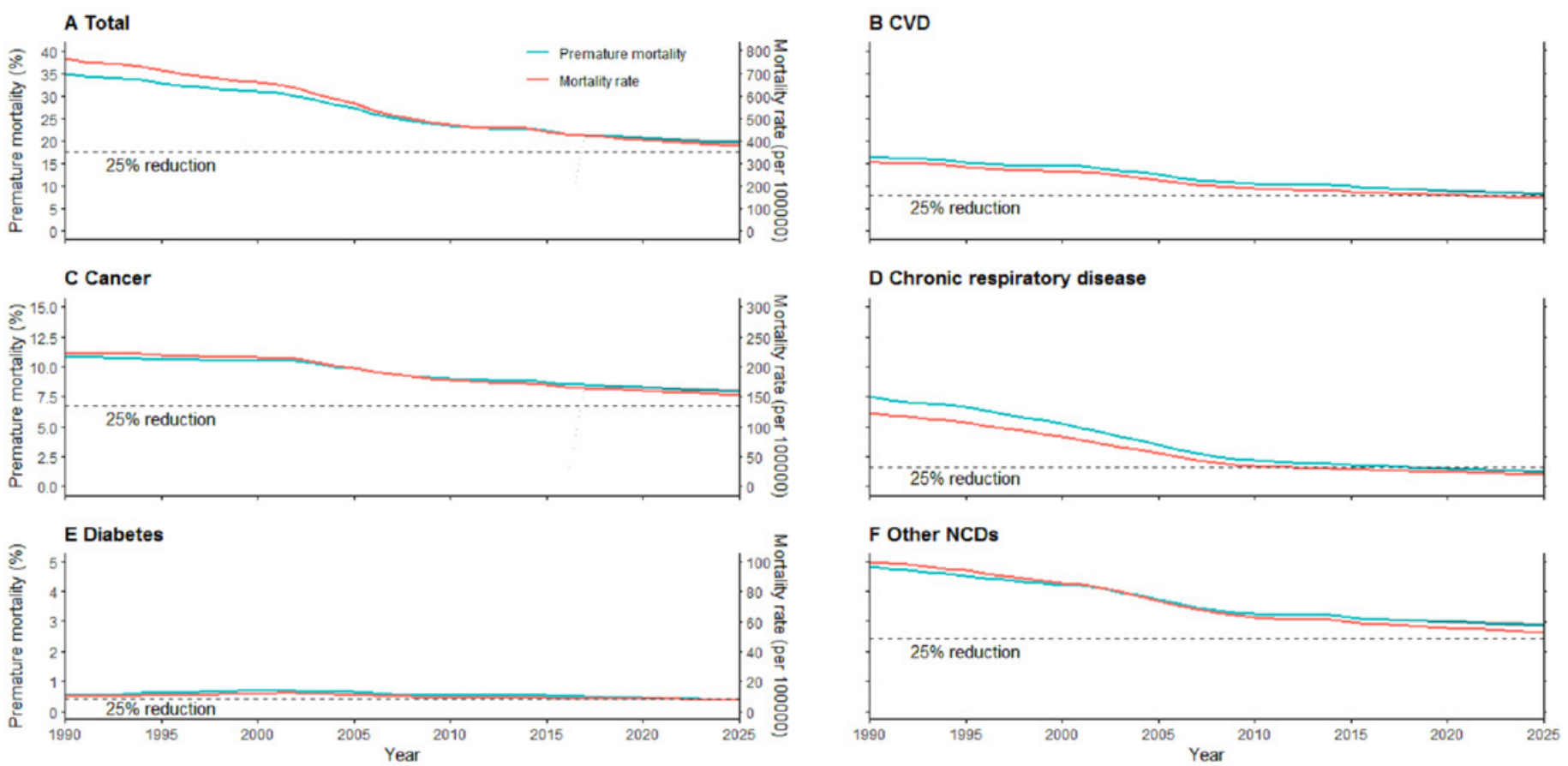


\section{Figure 2}

Observed and projected premature NCD mortality by sex in Hunan, China, 1990-2025

The black dashed line is used to distinguish observed years (1990-2016) from projected years (2017-2025). Five colored lines matching each chart area are shown for the target range and are used to test whether the target will be met (wider than the chart area in 2025) or not (narrower than the chart area).
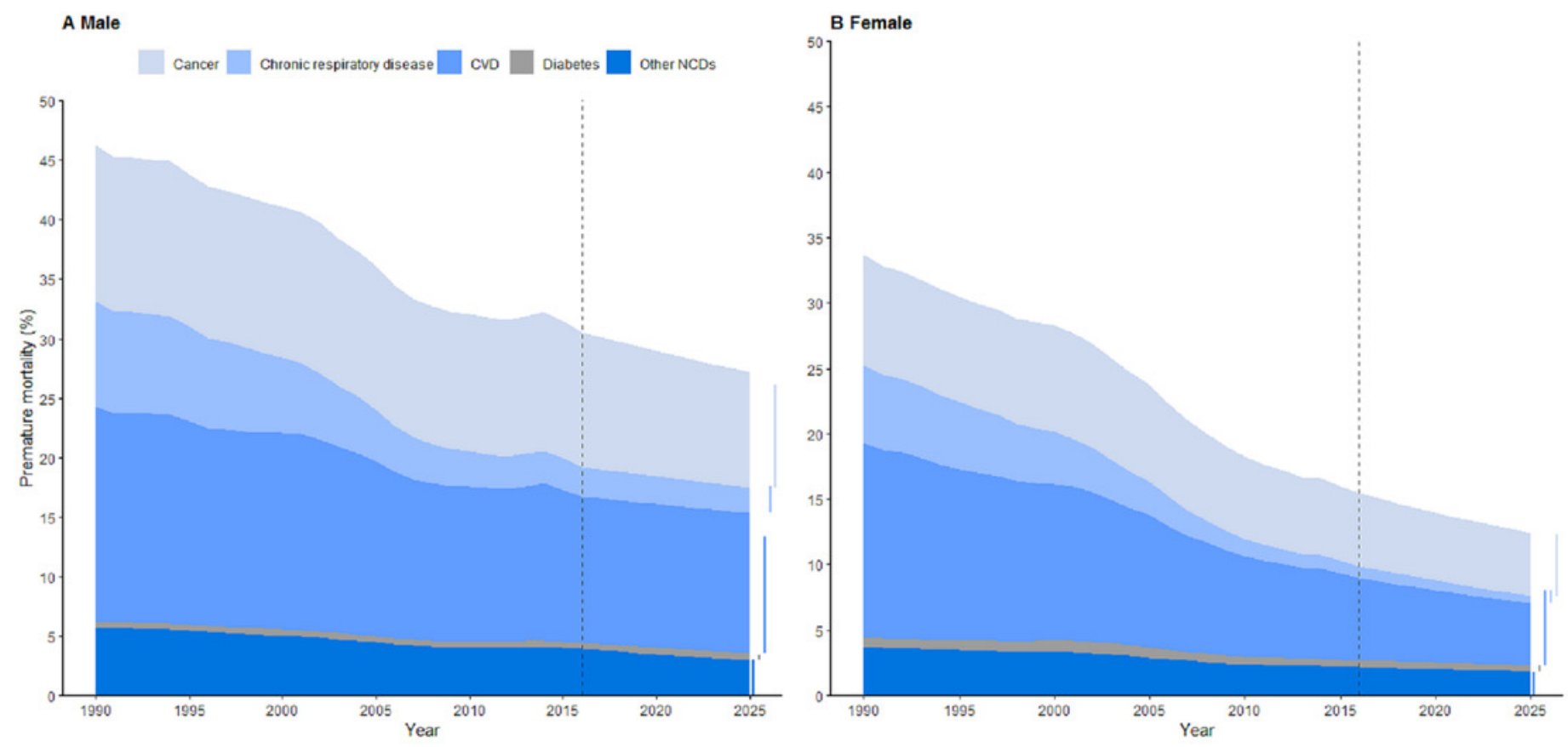
Figure 3

Excess premature mortality from NCDs in Hunan, China, 1990-2025

Yellow line: observed premature mortality from 1990 to 2016 and projected values from 2017 to 2025; grey line: favorable premature mortality from 1990 to 2025; blue area: total absolute excess premature mortality from the NCDs during the period.
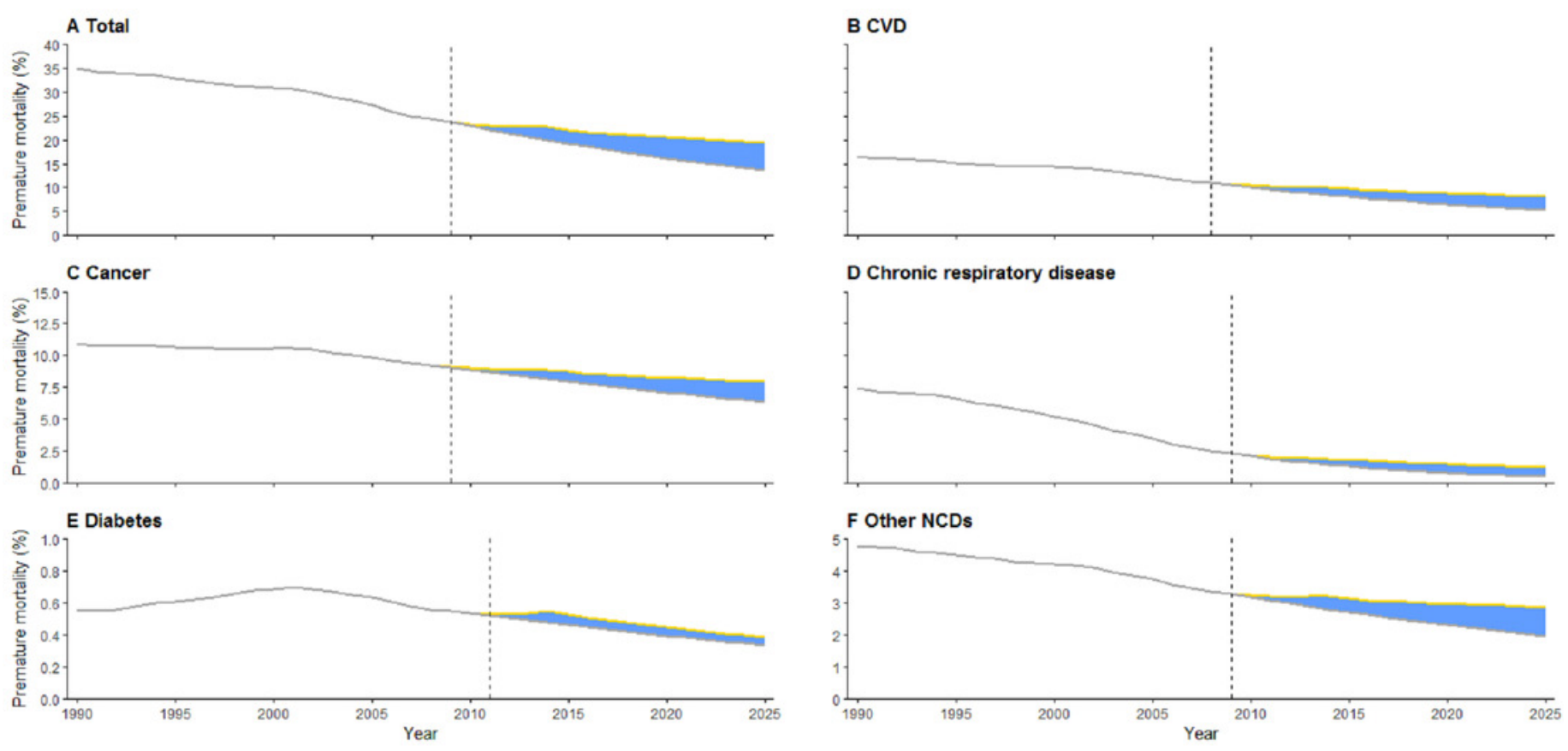


\section{Table $\mathbf{1}$ (on next page)}

Observed premature mortality from NCDs, ASRs in 2016 and predicted values for 2025, Hunan Province, China

Abbreviations: NCDs, non-communicable diseases; ASRs, age-standardized rates; $\mathrm{Cl}$, Confidential Interval; CVD, cardiovascular disease.

${ }^{a}$ Premature mortality was defined as the probability (\%) of dying aged 30-70 from NCDs.

${ }^{\mathrm{b}}$ Rates standardized to the 2010 China census population with age groups $30-34,35-39 \ldots$ and $65-79$ years, in per 100000 populations. 
Table 1. Observed premature mortality from NCDs, ASRs in 2016 and predicted values for 2025, Hunan Province, China

\begin{tabular}{|c|c|c|c|c|c|c|}
\hline \multirow[b]{2}{*}{ Sex } & \multirow[b]{2}{*}{ Diseases } & \multicolumn{2}{|c|}{ Observed 2016} & \multicolumn{2}{|l|}{ Predicted 2025} & \multirow[b]{2}{*}{$\begin{array}{l}\text {-Percent Change in } \\
\text { premature } \\
\text { mortality rate }\end{array}$} \\
\hline & & $\begin{array}{l}\text { premature } \\
\text { mortality rate } \\
\text { a }\end{array}$ & $\mathrm{ASR}^{\mathrm{b}}$ & $\begin{array}{l}\text { premature } \\
\text { mortality rate } \\
(95 \% \mathrm{CI})\end{array}$ & $\operatorname{ASR}(95 \% \mathrm{CI})$ & \\
\hline Both & Total & 21.5 & 428.8 & $19.5(19.0-20.1)$ & $\begin{array}{l}377.7(367.5- \\
387.8)\end{array}$ & -9.3 \\
\hline & Cancer & 8.5 & 166.6 & $7.9(7.8-8.1)$ & $\begin{array}{l}152.5(150.1- \\
154.9)\end{array}$ & -7.1 \\
\hline & CVD & 9.4 & 167.6 & $8.2(7.9-8.5)$ & $\begin{array}{l}143.7(139.4- \\
147.9)\end{array}$ & -12.8 \\
\hline & Diabetes & 0.5 & 8.6 & $0.6(0.5-0.6)$ & $7.9(7.5-8.3)$ & 20.0 \\
\hline & $\begin{array}{l}\text { Chronic respiratory } \\
\text { disease }\end{array}$ & 1.8 & 27.7 & $1.2(1.2-1.3)$ & $20.7(19.4-21.8)$ & -33.3 \\
\hline & Other NCDs & 3.1 & 58.3 & $2.9(2.8-3)$ & $52.8(51.9-53.8)$ & -6.5 \\
\hline Male & Total & 27.5 & 567.9 & $26.5(25.8-27.2)$ & $\begin{array}{l}531.4(518.7- \\
544.1)\end{array}$ & -3.6 \\
\hline & Cancer & 11.3 & 219.8 & $9.7(9.3-10.2)$ & $\begin{array}{l}210.1(206.3- \\
213.9)\end{array}$ & -14.2 \\
\hline & CVD & 12.3 & 223.4 & $11.8(11.3-12.3)$ & $\begin{array}{l}209.7(202.2- \\
217.4)\end{array}$ & -4.1 \\
\hline & Diabetes & 0.5 & 8.6 & $0.6(0.5-0.6)$ & $9.2(8.9-9.6)$ & 20.0 \\
\hline & $\begin{array}{l}\text { Chronic respiratory } \\
\text { disease }\end{array}$ & 2.5 & 39.6 & $2.1(1.9-2.3)$ & $30.9(29.7-32.3)$ & -16.0 \\
\hline & Other NCDs & 3.9 & 76.6 & $3(2.9-3.2)$ & 71.8(70.5-73.1) & -23.1 \\
\hline Female & Total & 14.7 & 281.1 & $11.7(11.3-12.1)$ & $\begin{array}{l}222.2(217.3- \\
226.9)\end{array}$ & -20.4 \\
\hline & Cancer & 5.6 & 110.2 & $4.8(4.7-4.9)$ & $94.2(92.6-95.8)$ & -14.3 \\
\hline
\end{tabular}




$\begin{array}{llllll}\text { CVD } & 6.3 & 108.3 & 4.8(4.5-5.0) & 80.6(77.3-84.0) & -23.8 \\ \begin{array}{l}\text { Diabetes } \\ \text { Chronic respiratory }\end{array} & 0.5 & 8.5 & 0.4(0.4-0.5) & 6.8(6.5-7.0) & -20.0 \\ \begin{array}{l}\text { disease } \\ \text { Other NCDs }\end{array} & 0.9 & 14.9 & 0.6(0.4-0.7) & 8.5(7.7-9.4) & -33.3 \\ & 2.2 & 39.1 & 1.9(1.8-1.9) & 32.5(32.1-33.0) & -13.6\end{array}$

2 Abbreviations: NCDs, non-communicable diseases; ASRs, age-standardized rates; CI, Confidential Interval; CVD, cardiovascular 3 disease.

4 a Premature mortality was defined as the probability (\%) of dying aged 30-70 from NCDs.

5 b Rates standardized to the 2010 China census population with age groups $30-34,35-39 \ldots$ and $65-79$ years, in per 100000 populations. 
Table 2 (on next page)

Verification results from Joinpoint model: Based on observed premature mortality from NCDs during 1990-2011 and projected values for 2012-2016 
1 Table 2. Verification results from Joinpoint model: Based on observed premature mortality from

2 NCDs during 1990-2011 and projected values for 2012-2016

\begin{tabular}{|c|c|c|c|c|c|c|}
\hline Sex & Items & 2012 & 2013 & 2014 & 2015 & 2016 \\
\hline \multirow[t]{5}{*}{ male } & projected data $^{1}$ & 28.19 & 27.88 & 27.58 & 27.28 & 26.98 \\
\hline & real data ${ }^{2}$ & 28.37 & 28.62 & 28.91 & 28.26 & 27.51 \\
\hline & $\operatorname{PE}(\%)$ & 0.65 & 2.59 & 4.61 & 3.47 & 1.93 \\
\hline & MAPE(\%) & 2.65 & & & & \\
\hline & MSE & 0.721 & & & & \\
\hline \multirow[t]{5}{*}{ female } & projected data & 16.03 & 15.49 & 14.96 & 14.46 & 13.97 \\
\hline & real data & 16.19 & 15.75 & 15.64 & 15.16 & 14.66 \\
\hline & PE(\%) & 0.99 & 1.67 & 4.32 & 4.64 & 4.68 \\
\hline & MAPE(\%) & 3.26 & & & & \\
\hline & MSE & 0.303 & & & & \\
\hline \multirow[t]{5}{*}{ both } & projected data & 22.56 & 22.15 & 21.74 & 21.34 & 20.94 \\
\hline & real data & 22.72 & 22.66 & 22.76 & 22.18 & 21.53 \\
\hline & $\operatorname{PE}(\%)$ & 0.70 & 2.24 & 4.48 & 3.79 & 2.74 \\
\hline & MAPE(\%) & 2.79 & & & & \\
\hline & MSE & 0.476 & & & & \\
\hline
\end{tabular}

$3{ }^{1}$ Projected data=premature mortality rate from all all NCDs combined projected for 2012-2016.

$4{ }^{2}$ Real data $=$ observed premature mortality rate from all all NCDs during 1990-2011.

5 Abbreviations: $\mathrm{MSE}=$ Mean Square Error, $\mathrm{PE}=$ Percentage Error, MAPE=Mean Absolute

6 Percentage Error. 